T. 2, № 1, 2020

УДК 621.313.3

I. Р. Гавдьо

Національний університет “Львівська політехніка", кафедра електромехатроніки та комп'ютеризованих електромеханічних систем, fireballua402@gmail.com

\title{
ОЦІНКА СТІЙКОСТІ ДО РОЗМАГНІЧУВАННЯ ДВИГУНА ПОСТІЙНОГО СТРУМУ ЗІ ЗБУДЖЕННЯМ ВІД ПОСТІЙНИХ МАГНІТІВ
}

https://doi.org/10.23939/sepes2020.01.036

(C) Гавдьо I. P., 2020

Двигуни постійного струму зі збудженням від постійних магнітів (ДПС ПМ) успішно замінюють аналогічні двигуни 3 електромагнітним збудженням, оскільки мають вищий коефіціснт корисної дії та меншу масу на одиницю потужності. Небезпека розмагнічування магнітів с однією з головних перешкод, яких треба уникнути в процесі проектування та експлуатації ДПС ПМ. Розмагнічувальна дія реакції якоря може призвести до розмагнічування постійних магнітів і до втрати працездатності двигуна, що й зумовлює актуальність досліджень. Метою статті є наближена оцінка стійкості до розмагнічування ДПС ПМ на основі спрощеної лінійної моделі. Стійкість до розмагнічування ДПС ПМ розглядається на прикладі поширеної двополюсної конструкції 3 радіально намагніченими магнітами. Показано, що для визначення положення робочої точки на діаграмі магніту ДПС ПМ графічним способом необхідно знати параметри магніту та магнітопроводу ДПС ПМ, а також визначити реакцію якоря $F_{a}$. Розглянуто три складові магніторушійної сили (МРС) якоря. Зроблено висновок, що доцільно враховувати найбілыш несприятливий випадок реакції якоря двигуна, коли вона приймасться еквівалентною їі поперечній складовій. Для оцінки стійкості до розмагнічування ДПС ПМ під час проектування, коли ще не розраховані потоки розсіяння магніту та характеристика намагнічування машини, використано заступну схему магнітного кола. Схема містить $n=3$ вузли i $m=5$ віток, намагнічувальні сили магніту $F_{m}$ i реакції якоря $F_{a}$. На схемі наведено магнітні опори: $R_{m}-$ постійного магніту; $\boldsymbol{R}_{\delta}$ - повітряного проміжку; $\boldsymbol{R}_{c m}$ - сталі магнітопроводу; $\boldsymbol{R}_{\sigma m}$ - розсіяння магніту; $\boldsymbol{R}_{\sigma a}$ - розсіяння якоря. Заступну схему описано системою лінійних рівнянь, складених за законами Кірхгофа. Знайдено розв'язок системи відносно невідомого потоку постійного магніту $\Phi_{m}$. Характеристику розмагнічування магніту В (Н) наведено у вигляді рівняння прямої. Отримано остаточну формулу для максимально допустимої величини реакції якоря $\boldsymbol{F}_{a \max }$, яка не призведе до втрати постійним магнітом магнітних властивостей. Цією формулою доцільно скористатися на початковому етапі проектування ДПС ПМ.

Ключові слова: двигун постійного струму, збудження від постійних магнітів, реакція якоря, розмагнічувальна дія, параметри магніту, параметри магнітного кола. 


\section{Постановка проблеми}

ДПС ПМ успішно замінюють двигуни постійного струму із електромагнітним збудженням, оскільки мають низку переваг порівняно з ними: високий коефіцієнт корисної дії внаслідок відсутності втрат на збудження та меншу масу на одиницю потужності. Цей тип двигунів застосовують в автомобілях, побутовій техніці, переносному електроінструменті [1]. В окремих випадках, наприклад, в автомобільних стартерах, великі пускові струми спричиняють значну розмагнічувальну дію реакції якоря, що ускладнює застосування ДПС ПМ [2]. Небезпека розмагнічування магнітів $\epsilon$ однією з головних перешкод, яких треба уникнути в процесі проєктування і експлуатації ДПС ПМ.

\section{Актуальність досліджень}

Під час проєктування ДПС ПМ необхідно враховувати розмагнічувальну дію реакції якоря, яка може призвести до розмагнічування постійних магнітів, а отже, до втрати працездатності двигуна, чим зумовлена актуальність досліджень.

\section{Мета та завдання статті}

Метою статті $є$ оцінювання стійкості до розмагнічування ДПС ПМ на основі спрощеної лінійної моделі. В статті вирішуються такі завдання: складено спрощену заступну схему магнітного кола ДПС ПМ двополюсної конструкції з радіальними магнітами; наведено систему рівнянь, які іiі описують; виведено вираз для максимального значення реакції якоря, яка не призводить до втрати магнітних властивостей постійних магнітів.

\section{Аналіз останніх досліджень}

У [2] проаналізовано стійкість до розмагнічування взірців ДПС ПМ, які використовувалися як двигуни - стартери. Розрахунки виконано на основі поєднання польових методів і методів теорії кіл. Результати показали, що допустима величина струму якоря, який не спричиняє розмагнічування магнітів, $\epsilon$ практично пропорційною до їх довжини у напрямі намагнічування.

Рівняння, які використовуються під час проектування двигуна 3 нерухомим трифазним якорем із обмотками керування та ротором з постійними магнітами, викладено в [3]. Автором на основі лінійної фізичної моделі виведено формулу для максимального значення реакції якоря, яка не призводить до незворотних втрат магнітних властивостей постійного магніту.

Аналіз стійкості до розмагнічування ДПС ПМ на основі колових методів [4] або методів поля [1] дає змогу отримати достовірні результати, однак $є$ трудомістким. Тому, на наш погляд, на початковому етапі проектування ДПС ПМ для наближених розрахунків доцільно використовувати результати, отримані з використанням спрощеної лінійної моделі.

\section{Виклад основного матеріалу}

Стійкість до розмагнічування ДПС ПМ оцінимо на прикладі поширеної двополюсної конструкції з радіально намагніченими магнітами (рис. 1), де $\delta$ - повітряний проміжок; $h_{m}-$ довжина (товщина) магніту у напрямі намагнічування.

Розглянемо визначення положення робочої точки на діаграмі магніту ДПС ПМ (рис. 2) в осях $B-H$ за умови, що магніт має прямолінійну характеристику розмагнічування (справедливо для більшості сучасних матеріалів). Для визначення положення робочої точки на діаграмі магніту графічним способом виконують такі побудови $[5,6]$ :

a) характеризують розмагнічування магніту 1 за величинами залишкової індукції $B_{r}$ та коерцитивної сили $H_{c}$;

б) проводять пряму провідності потоків розсіяння 2 під кутом $\alpha_{\sigma}$, який визначається за формулою $\operatorname{tg} \alpha_{\sigma}=\Lambda_{\sigma}\left(2 h_{m} / S_{m}\right)=\lambda_{\sigma}$, де $\Lambda_{\sigma}$ - повна магнітна провідність полів розсіяння магніту; $\lambda_{\sigma}-$ зведена магнітна провідність полів розсіяння; $S_{m}$ - площа нейтрального перетину магніту:

в) від ординат прямої 1 віднімають відповідні ординати прямої 2 і отримують пряму 3 залежність індукції у повітряному проміжку $B_{\delta}$ від напруженості поля $H$ на полюсах магніту;

г) характеристику намагнічування машини $\Phi_{\delta}=f(F)$ перераховують в координатах $B_{\delta}=f(H)$ і будують на діаграмі (крива 4); робоча точка А з врахуванням потоків розсіяння та спаду магнітної напруги на феромагнітних ділянках магнітопроводу визначається перетином прямої 3 із кривою 4; 


\section{I. Р. Гавдьо}

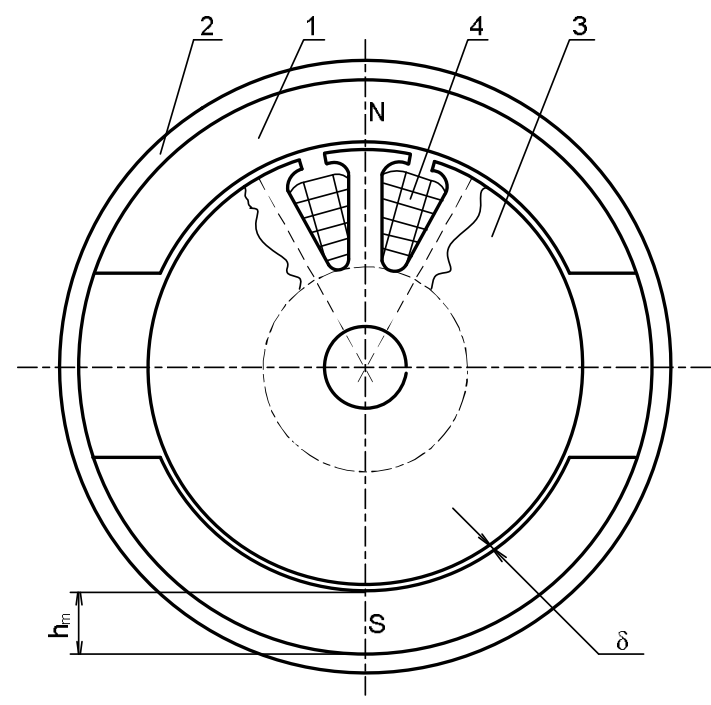

Рис. 1. Ескіз двигуна постійного струму з радіально намагніченими магнітами:

1 - постійний магніт; 2 - феромагнітне ярмо статора; 3 -якір; 4-обмотка якоря

д) для визначення положення робочої точки, яка характеризує стан магніту при дії розмагнічувальної реакції якоря $F_{a}$, необхідно точки кривої намагнічування 4 змістити вліво від початку координат на відрізок, який відповідає величині $H_{a}=F_{a} / 2 h_{m}$.; перетин зміщеної кривої намагнічування 5 з прямою 3 визначає робочу точку магніту К.

Отже, для визначення положення робочої точки на діаграмі магніту необхідно знати параметри матеріалу магніту $\left(B_{r}\right.$ та $\left.H_{c}\right)$, розміри магніту та магнітопроводу ДПС ПМ для побудови прямої провідності потоків розсіяння та характеристики намагнічування, а також визначити реакцію якоря $F_{a}$.

В умовах роботи колекторного мікродвигуна під навантаженням на магнітне поле повітряного проміжку суттєво впливає реакція якоря, яка може проявлятися у вигляді трьох складових МРС якоря: поперечної, поздовжньої та комутаційної. Відомо, що у випадку насичення магнітного кола поперечна МРС якоря $F_{a q}$ завжди спричиняє послаблення поля машини, а поздовжня та комутаційна МРC $F_{a d}$ i $F_{k}$ в електродвигунах малої потужності підсилюють його.

Отже, сумарна МРС якоря мікродвигуна у випадку навантаження становитиме [7]:

$$
F_{a}=F_{a q}-F_{a d}-F_{k}
$$

Поздовжня складова МРС якоря

$$
F_{a d}=b_{d} A, \mathrm{~A},
$$

де $b_{d}=(0,15 \ldots 0,3) 10^{-3}$, м - можливе самовільне зміщення щіток з геометричної нейтралі внаслідок механічних причин і неточності встановлення. Величина поздовжньої складової МРС якоря $F_{d} €$ незначною і нею можна знехтувати.

Поздовжня комутаційна МРС якоря $F_{k}$ у машинах малої потужності виникає внаслідок зміщення нейтральної точки обмотки 3 геометричної нейтралі в умовах сповільненої комутації струму в короткозамкнених секціях, i $€$ в мікродвигунах намагнічувальною стосовно поля полюсів. Знехтуємо величиною $F_{k}$, яка зазвичай підсилює поле полюсів, і аналітичні вирази для іiі розрахунку $є$ достатньо складними.

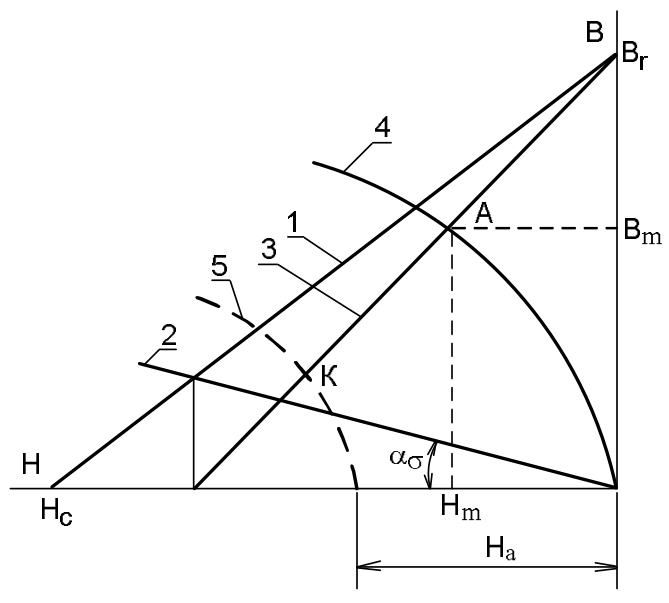

Рис. 2. Робоча діаграма магніту

Припустимо, що $F_{a} \approx F_{a q}$, тобто розглянемо найбільш несприятливий випадок реакції якоря для електродвигуна.

На рис. 3 показано розгорнутими структури якоря та постійні магніти у випадку розташування щіток по поперечній осі $q$ на геометричній нейтралі. Тоді реакція якоря $\epsilon$ поперечною - вісь поля якоря збігається з поперечною віссю $q$ машини. За умови достатньо великої кількості провідників на полюсній поділці намагнічуюча сила розподіленої обмотки якоря має форму, показану на рис. 3.

Намагнічувальна сила поперечної реакції якоря, яка припадає на один проміжок, на віддалі $x$ від осі $d$ становитиме

$$
F_{a q x}= \pm x A,
$$


де $A=\left(I_{a} N /\left(2 a \pi D_{a}\right)\right.$ - лінійне навантаження якоря; $I_{a}$ - струм якоря; $N, a$ - кількість провідників та паралельних гілок якоря відповідно; $D_{a}-$ зовнішній діаметр якоря.

Максимальна намагнічувальна сила реакції якоря, яка діє на край постійного магніту, становитиме

$$
F_{a \max }= \pm\left(b_{p} / 2\right) A .
$$

Для оцінювання стійкості до розмагнічування ДПС ПМ під час проектування, коли ще не розраховані потоки розсіяння магніту та характеристика намагнічування машини, використаємо заступну схему магнітного кола [8], наведену на рис. 4. Схема містить $n=3$ вузли і $m=5$ віток, намагнічувальні сили магніту $F_{m}$ і реакції якоря $F_{a}$.

На схемі наведено такі магнітні опори: $R_{m}$ - постійного магніту; $R_{\delta}$ - повітряного проміжку; $R_{c m}$ - сталі магнітопроводу; $R_{\sigma m}$ - розсіяння магніту; $R_{\sigma a}$ - розсіяння якоря. Невідомими $\epsilon$ магнітні потоки: $\Phi_{m}-$ постійного магніту; $\Phi_{\delta}-$ повітряного проміжку; $\Phi_{a}-$ якоря; $\Phi_{\sigma m}$ - розсіяння магніту; $\Phi_{\sigma a}-$ розсіяння якоря.

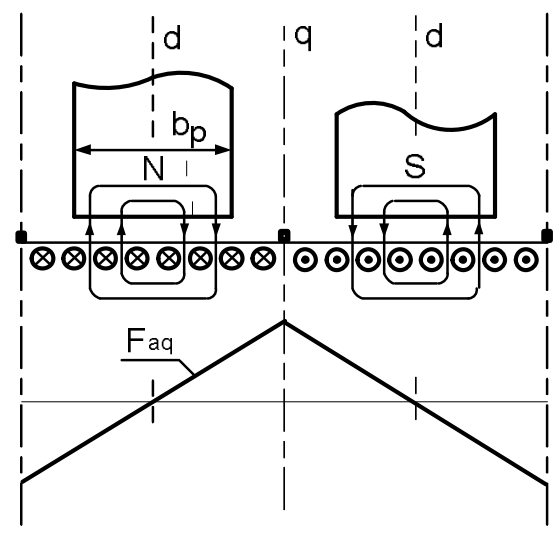

Рис. 3. Реакиія якоря в ДПС ПМ

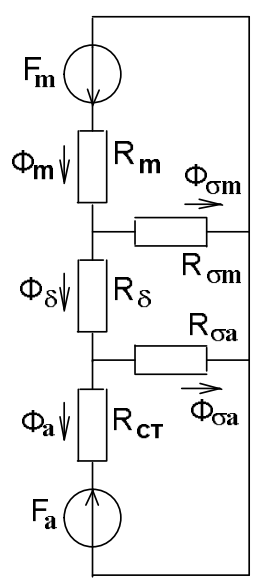

Рис. 4. Заступна схема магнітного кола ДПС ПМ

Складена за законами Кірхгофа система лінійних рівнянь, яка описує заступну схему магнітного кола, має вигляд:

$$
\begin{gathered}
\Phi_{m}=\Phi_{\delta}+\Phi_{\sigma m} ; \\
\Phi_{\delta}=\Phi_{a}+\Phi_{\sigma a} ; \\
F_{m}=R_{m} \Phi_{m}+R_{\sigma m} \Phi_{\sigma m} ; \\
0=R_{\delta} \Phi_{\delta}+R_{\sigma a} \Phi_{\sigma a}-R_{\sigma m} \Phi_{\sigma m} ; \\
-F_{a}=R_{c m} \Phi_{a}-R_{\sigma a} \Phi_{\sigma a} .
\end{gathered}
$$

Виразивши з (5a) i (5б) потоки $\Phi_{\sigma \mathrm{m}}$ i $\Phi_{\sigma а}$ і підставивши їх в (5в)-(5д), отримаємо:

$$
\begin{gathered}
F_{m}=R_{m} \Phi_{m}+R_{\sigma m}\left(\Phi_{m}-\Phi_{\delta}\right) ; \\
0=R_{\delta} \Phi_{\delta}+R_{\sigma a}\left(\Phi_{\delta}-\Phi_{a}\right)-R_{\sigma m}\left(\Phi_{m}-\Phi_{\delta}\right) ; \\
-F_{a}=R_{c m} \Phi_{a}-R_{\sigma a}\left(\Phi_{\delta}-\Phi_{a}\right) .
\end{gathered}
$$

Знайдемо розв'язок системи (6) стосовно невідомого магнітного потоку $\Phi_{m}$; для спрощення допустимо, що $R_{\sigma a} /\left(R_{\sigma a}+R_{c m}\right) \approx 1$, тобто знехтуємо величиною $R_{c m}$ порівняно з $R_{\sigma a}$; позначимо $R_{\delta}+R_{c m}=k_{\mu} R_{\delta}$, де $k_{\mu}=\left(R_{\delta}+R_{c m}\right) / R_{\delta}-$ коефіцієнт насичення сталі.

У результаті отримаємо

де

$$
\Phi_{m}=\left(F_{m} \xi_{m}-F_{a}\right) /\left(R_{m} \xi_{m}+k_{\mu} R_{\delta}\right)
$$

$$
\xi_{m}=1+\left(k_{\mu} R_{\delta} / R_{\sigma m}\right) .
$$




\section{I. Р. Гавдьо}

Перетворимо (7) так, щоби виразити величину розмагнічуючої реакції якоря $F_{a}$ через відомі параметри магніту та параметри магнітного кола ДПС ПМ, якими наближено можна задатися на початковій стадії проектування.

Запишемо рівняння прямої розмагнічування магніту у вигляді

$$
B_{m}=B_{r}-H_{m}\left(B_{r} / H_{c}\right) .
$$

Врахуємо, що $B_{r} / H_{c}=\mu_{a}=\mu_{0} \mu_{m}$, де $\mu_{m}, \mu_{a}$ - відносна та абсолютна магнітні проникності магніту; $\mu_{0}=4 \pi 10^{-7} \Gamma_{\mathrm{H}} / \mathrm{M}$.

Тоді (9) подамо у вигляді

$$
B_{m}=B_{r}-\mu_{0} \mu_{m} H_{m}
$$

Для магнітних опорів $R_{\delta}, R_{m}$ та магнітного потоку $\Phi_{m}$ запишемо співвідношення

$$
\begin{aligned}
& \Phi_{m}=S_{m} B_{m} ; \\
& R_{m}=2 h_{m} H_{c} / S_{m} B_{r} ; \\
& R_{\delta}=2 \delta k_{\delta} / \mu_{0} S_{\delta},
\end{aligned}
$$

де $k_{\delta}$ - коефіцієнт Картера; $S_{\delta}$ - площа повітряного проміжку під магнітом.

Враховуючи (10) - (13), за виразом (7) отримуємо значення напруженості поля у магніті $H_{m}$

$$
H_{m}=\left[\mu_{m} H_{c} 2 \delta k_{\delta}\left(S_{m} / S_{\delta}\right)+F_{a}\right] /\left[2 h_{m} \xi_{m}+2 \delta k_{\delta} \mu_{m}\left(S_{m} / S_{\delta}\right)\right] .
$$

Нехай напруженість поля у постійному магніті досягає свого критичного значення $H_{\text {ткр }}$. Введемо коефіцієнт запасу $k_{\text {заn }}=H_{m к р} / H_{c} \approx(0,7-0,75)$, який враховує неточності розрахунку.

За (14) отримуємо остаточний вираз для максимально допустимої величини реакції якоря $F_{a \max }$, яка не призведе до втрати постійним магнітом магнітних властивостей

$$
F_{a \max } \leq 2 h_{m} \xi_{m} k_{3 a n} H_{c}-2 \delta k_{\delta} \mu_{m}\left(1-k_{3 a n}\right) H_{c}\left(S_{m} / S_{\delta}\right) \text {. }
$$

Формулою (15) можна скористатися на початку проєктування ДПС ПМ, коли відомі параметри матеріалу магнітів $\left(H_{c}, B_{r}\right)$, лінійне навантаження $A$, діаметр і довжина пакета якоря $\left(D_{a}\right.$, $l_{\delta}$ ), прийняті розміри магніту $h_{m}$ та $b_{p}$, величина повітряного проміжку $\delta$ і коефіцієнт Картера $k_{\delta}$. Необхідно наближено розрахувати $R_{\sigma m}$ та прийняти коефіцієнт насичення $k_{\mu}$, щоб за (8) розрахувати $\xi_{m}$. Для вибраного матеріалу магніту стійкість магнітів до розмагнічування, як випливає 3 (15), залежить передусім від довжини магніту у напрямі намагнічування $h_{m}$.

\section{Висновки}

Отриманий вираз для максимального значення реакції якоря, яка не призводить до втрати магнітних властивостей постійних магнітів, може бути використаний під час проєктування ДПС ПМ.

\section{Перспективи подальших досліджень}

Надалі необхідно дослідити стійкість до розмагнічування ДПС ПМ із використанням математичної моделі цього типу двигуна на основі теорії електричних та магнітних кіл.

\section{Список використаних літературних джерел}

1. Jacek F. Gieras. Permanent magnet motor technology / Jacek F. Gieras // Design and applications. CRC Press Taylor and Francis Group. London, New Jork, 2010.

2. Dudzikowski I. Silniki komutatorowe wzbudzane magnesami trwalymi. / I. Dudzikowski // Prace Naukowe Instytutu Maszyn, Napędów i Pomiarów Elektrycznych Politechniki Wrocławskiej, No. 58, Studia i Materiaty № 25, 2005.

3. Белый П. Н. Уравнения для проектирования встраиваемых магнитоэлектрических двигателей дискового типа / П. Н. Бельій // Технічна електродинаміка. 2005, № 6, с. 53-56.

4. Maliar V. Mathematical model of permanent magnets direct current motor / V. Maliar, I. Havdo // Computational Problems of Electrical Engineering. Львiв, 2015, No. 1, Vol. 5, p. 33-36.

5. Тазов Г. В. Автоматизированное проектирование электрических машин малой мощности / Тазов Г. В., Хрущев В. В. Л.: Энергоатомиздат, 1991. 336 с. 
6. Jacek F. Gieras. Projektowanie silnikow produ stalego malej mocy o magnesach trwalych wspomagane maszyna cyfrowa / Jacek F. Gieras, G. Frydrychowicz, W. Jozefowicz // Przeglad elektrotechniczny R. LIV Z. 4/1978.

7. Лифанов В. А. Расчет электрических машин малой мощности: учеб. пособ. / В. А. Лифанов, Г. В. Помогаев, Н. П. Ермолин. Челябинск: Изд-во ЮУрГУ, 2008. 127 с.

8. Jacek F. Gieras . Calculation of the steady state performance for small commutator permanent magnet DC motors: classical and finite element approaches / Jacek F. Gieras, Mitchell Wind // IEEE Transactions on magnetic, Vol. 28, No. 5, September 1992.

\title{
References
}

1. Jacek F. Gieras. Permanent magnet motor technology. / Jacek F. Gieras // Design and applications. CRC Press Taylor and Francis Group. London, New Jork, 2010.

2. Dudzikowski. I. Silniki komutatorowe wzbudzane magnesami trwalymi / I. Dudzikowski // Prace Naukowe Instytutu Maszyn, Napędów i Pomiarów Elektrycznych Politechniki Wrocławskiej, No. 58, Studia i Materiały No. 25, 2005 .

3. Belyi P. N. Uravnienia dla proektirovania vstraivaemych magnitoelektriczeskich dvigatelej diskovoho tipa / P. N. Belyi // Techniczna elektrodynamika. 2005, No. 6, p. 53-56.

4. Maliar V. Mathematical model of permanent magnets direct current motor / V. Maliar, I. Havdo // Computational Problems of Electrical Engineering. Lviv, 2015, No. 1, Vol. 5, p. 33-36.

5. Tazov H. V. Avtomatizirovannoe proektirovanie elektriczeskich mashyn maloj moscznosti / Tazov H. V., Chrushchev V. V. L.: Enerhoatomizdat, 1991.336 p.

6. Jacek F. Gieras. Projektowanie silnikow produ stalego malej mocy o magnesach trwalych wspomagane maszyna cyfrowa / Jacek F. Gieras, G. Frydrychowicz, W. Jozefowicz // Przeglad elektrotechniczny R. LIV Z. 4/1978.

7. Lifanov V. A. Rasczet elektriczeskich mashyn maloj moscznosti: uczebnoe posobie / V. A. Lifanov, H. V. Pomohaev, N. P. Ermolin // Czeljabinsk: Izd-vo JuUrHU, 2008. 127 p.

8. Jacek F. Gieras. Calculation of the steady state performance for small commutator permanent magnet DC motors: classical and finite element approaches / Jacek F. Gieras, Mitchell Wind // IEEE Transactions on magnetic, Vol. 28, No. 5, September 1992.

I. Havdo

Lviv Polytechnic National University, Department of Electromechatronics and Computerized Electromechanical Systems, fireballua402@gmail.com

\author{
FIRMNESS TO DEMAGNETIZATION EFFECT \\ OF PERMANENT MAGNET D.C. MOTOR ESTIMATION
}

(a) Havdo I., 2020

Permanent magnet direct current (PMDC) motors nowadays successfully replace analogical motors with electromagnetic excitation. PMDC have a higher output-input ratio and less mass on unit of power. In the process of planning and exploitation of PMDC motors it is necessary to prevent the danger of demagnetization effect of permanent magnets. The demagnetizing action of armature reaction can result in demagnetization effect of permanent magnets and to the loss of capacity to the PMDC. These factor ground research actuality. The aim of the article is a rough estimate of firmness to demagnetization effect of PMDC motor on the basis of the simplified linear model. Firmness to demagnetization effect of PMDC motor is examined on the example of widespread bipolar construction with the magnets which magnetized in radial direction. Position-finding of operating point is considered on a diagram to the magnet of PMDC motor with the use of graphic method. For this realization it is necessary to know parameters to the magnet and magnetic core of PMDC motor and also to define the reaction of anchor $F_{a}$. It is considered three components of magnetomotive force (MMF) of armature. It is necessary to take into account the most unfavorable case of reaction of armature of PMDC motor, when this reaction is accepted by equivalent it to the cross component. For the estimation of firmness to 


\section{I. Р. Гавдьо}

demagnetization effect of PMDC motor the equivalent circuit of magnetic core is used. On this stage of planning to the PMDC motor the yet not expected leakage fluxes of the magnet and saturation characteristic of motor. An equivalent circuit contains MMF of the magnet $F_{m}$ and reactions of armature $F_{a}$ and magnetic resistance. An equivalent circuit is described by the system of linear equations that is made after the Kirchhoff's circuit laws. The decision of the system is found in relation to unknown magnetic flux of permanent magnet $\Phi_{m}$. Demagnetization curve of the magnet $B(H)$ is presented as equation of line. The final formula is got for the maximally possible value of reaction of armature $F_{a \max }$, that will not result in the loss of magnetic properties a permanent magnet. This formula it is expedient to use on the initial stage of planning of PMDC motor.

Key words: permanent magnet d. c. motor, armature reaction, demagnetizing effect, parameters of permanent magnet, parameters of magnetic circuit,. 